\title{
Passive and active contributions to generated force and retraction in heart valve tissue engineering
}

\author{
Marijke A. A. van Vlimmeren • Anita Driessen-Mol • \\ Cees W. J. Oomens • Frank P. T. Baaijens
}

Received: 4 August 2011 / Accepted: 27 December 2011 / Published online: 14 January 2012

(C) The Author(s) 2012. This article is published with open access at Springerlink.com

\begin{abstract}
In tissue engineered heart valves, cell-mediated stress development during culture results in leaflet retraction at time of implantation. This tissue retraction is partly active due to traction forces exerted by the cells and partly passive due to release of residual stress in the extracellular matrix and the cells. Within this study, we unraveled the passive and active contributions of cells and matrix to generated force and retraction in engineered heart valve tissues. Tissue engineered rectangular strips, fabricated from PGA/P4HB scaffolds and seeded with human myofibroblasts, were cultured for 4 weeks, after which the cellular contribution was changed at different levels. Elimination of the active cellular traction forces was achieved with Cytochalasin D and inhibition of the Rho-associated kinase pathway. Both active and passive cellular contributions were eliminated by lysation and/or decellularization of the tissue. Maximum cell activity was reached by increasing the fetal bovine serum
\end{abstract}

M. A. A. van Vlimmeren $(\varangle)$

Department of Biomedical Engineering, WH4.12, Eindhoven University of Technology, PO Box 513, 5600 MB, Eindhoven, The Netherlands

e-mail: m.a.a.v.vlimmeren@tue.nl

A. Driessen-Mol

Department Biomedical Engineering, WH4.111, Eindhoven University of Technology, PO Box 513, 5600 MB, Eindhoven,

The Netherlands

C. W. J. Oomens

Department Biomedical Engineering, WH4.124, Eindhoven University of Technology, PO Box 513, 5600 MB, Eindhoven,

The Netherlands

F. P. T. Baaijens

Department Biomedical Engineering, WH4.137, Eindhoven

University of Technology, PO Box 513, 5600 MB, Eindhoven, The Netherlands concentration to $50 \%$. The generated force decreased $\sim 20 \%$ after elimination of the active cellular component, $\sim 25 \%$ when the passive cellular component was removed as well and remained unaffected by increased serum concentrations. Passive retraction accounted for $\sim 60 \%$ of total retraction, of which $\sim 15 \%$ was residual stress in the matrix and $\sim 45 \%$ was passive cell retraction. Cell traction forces accounted for the remainder $\sim 40 \%$ of the retraction. Full activation of the cells increased retraction by $\sim 45 \%$. These results illustrate the importance of the cells in the process of tissue retraction, not only actively retracting the tissue, but also in a passive manner to a large extent.

Keywords Heart valve tissue engineering - Stress generation - Passive and active retraction - Extracellular matrix . Myofibroblasts

\section{Introduction}

Heart valve tissue engineering is a widely investigated technology in the field of regenerative medicine as an alternative for current available heart valve replacements. Tissue engineered heart valves provide viable implants, which may have the capacity to grow, remodel, and repair throughout a patient's life. For pediatric patients this would prevent dangerous re-operations throughout their childhood to accommodate growth. Over the last decade, bioreactor systems inducing mechanical conditioning and flow profiles have improved in vitro tissue formation (Flanagan et al. 2007; Mol et al. 2005; Kortsmit et al. 2009; Ruel and Lachance 2009; Syedain and Tranquillo 2009). Moreover, in vivo animal studies have demonstrated the feasibility of heart valve tissue engineering, showing remodeling into native-like structures (Hoerstrup et al. 2000; Sodian et al. 2000; Stock et al. 2000; 
Sutherland et al. 2005; Gottlieb et al. 2010; Schmidt et al. 2010; Flanagan et al. 2009). However, there are still some challenges that need to be overcome. One of those challenges is cell-mediated leaflet retraction, causing regurgitation in vivo (Flanagan et al. 2009; Gottlieb et al. 2010; Syedain et al. 2011). In general, this regurgitation has been neglected and reported to be only mild. However, it is observed in every in vivo study and should be considered a serious issue that needs to be addressed.

Leaflet retraction is a cell-mediated problem, caused by traction forces that the cells exert on their surroundings. Cells will always aim to develop an internal stress homeostasis and adjust their traction forces to retain this in response to environmental changes (Brown et al. 1998; Mizutani et al. 2004). Increased traction forces are observed upon a decrease of mechanical loading, while a decrease is observed upon increased mechanical loading (Brown et al. 1998; Mizutani et al. 2004). Within the field of heart valve tissue engineering, the effects of these cell traction forces are controversial. During constrained tissue culture, the traction forces of the cells allow them to remodel their surroundings, which results in compaction of the tissue and the generation of pre-stress within the extracellular matrix (ECM) (Balestrini and Billiar 2009; Van Vlimmeren et al. 2011). This stress development within the cells and matrix is beneficial for tissue formation (Mol et al. 2006) and provides an oriented collagen network (Robinson et al. 2008; Neidert and Tranquillo 2006). However, upon release of constraints the developed pre-stress in the ECM and cells causes immediate retraction of the tissue (passive process), after which the cells start to remodel their surroundings in an attempt to re-establish their desired internal stress level (active process), leading to additional retraction (Balestrini and Billiar 2009). To prevent leaflet retraction in heart valve tissue engineering, these passive and active processes need to be unraveled and quantified.

Cell traction forces are transmitted from the intracellular network of actin fibers to the surrounding ECM via focal adhesions that consist of complex anchoring proteins, such as aggregated integrins, vinculin, paxin, tensin, and focal adhesion kinase (Dugina et al. 2001; Hinz and Gabbiani 2003; Hinz 2006). Intracellular, traction forces are generated by actin-myosin contraction, which is promoted by phosphorylation of myosin light chain (MLC). In myofibroblasts, this actin-myosin contraction is mediated by the Rho A and Rho-associated kinase (ROCK) pathway, which blocks MLC phosphatase and directly phosphorylates MLC (Yee et al. 2001; Nobe et al. 2010; Dallon and Ehrlich 2010; Follonier Castella et al. 2010). Traction forces can be blocked by the disruption of actin fibers or inhibition of the ROCK pathway, and increased by enhancement of the serum concentration in the culture medium (Grouf et al. 2007; Wakatsuki et al. 2000; Nobe et al. 2010). Blocking traction forces, the active cellular component of retraction can be eliminated.
Active and passive phenomena have been investigated thoroughly in short-term studies with fibroblast-populated collagen and fibrin gel systems (Legant et al. 2009; Marquez et al. 2009; John et al. 2010; Youssef et al. 2011; Tomasek et al. 1992; Grouf et al. 2007; Balestrini and Billiar 2009). In tissue engineered heart valves, the ECM is developed during 4 weeks of tissue culture and is more mature than the generally investigated collagen and fibrin gels. Tissue retraction and remodeling is less easy in such a developed tissue, as the surroundings of the cells are stiffer. Therefore, this study quantified the passive and active contributions to generated force and retraction in engineered heart valve tissues. This was performed in a model system of tissue engineered constructs, fabricated from vascular-derived cells seeded onto a biodegradable scaffold. First, the active cellular traction forces were eliminated by the disruption of the actin fibers with Cytochalasin D (CytoD) and the inhibition of the ROCK pathway by Y-27632. As force and retraction remained substantial, total cellular contribution (both passive and active) was eliminated next, by lysation of the cells and decellularization of the tissue. Furthermore, maximum retraction was investigated by increasing the concentration of serum.

\section{Material and methods}

\subsection{Tissue culture}

Human vascular-derived cells were harvested from the vena saphena magna obtained according to the Dutch guidelines for secondary used materials. Cells were expanded using standard cell culture methods in a humidified atmosphere containing $5 \% \mathrm{CO}_{2}$ at $37^{\circ} \mathrm{C}$. Culture medium consisted of advanced Dulbecco's Modified Eagle Medium (DMEM; Invitrogen, Carlsbad, USA), supplemented with 10\% Fetal Bovine Serum (FBS; Greiner Bio one, Frickenhausen, The Netherlands), $1 \%$ GlutaMax (Invitrogen), and 1\% penicillin/streptomycin (Lonza, Basel, Switzerland).

Rectangular tissue engineered strips (referred to as TE constructs) were cultured in a previously described model system which is shown in Fig. 1a (Van Vlimmeren et al. 2011). Briefly, the TE constructs were cultured in between two sliding blocks positioned in a metal frame. One of the sliding blocks was fixed to the metal frame via two leaf springs and the displacement of this sliding block correlated to the generated force (Fig. 1b, d). Because the force generated by the cells during culture deformed the leaf springs, it was defined as semi-constrained culture. The opposite sliding block was fixated during culture and used to measure retraction after release of the constraints at the end of the culture period (Fig. 1c, e).

To fabricate the TE constructs, the cells were seeded onto rectangular-shaped scaffolds $(18 \times 5 \times 1 \mathrm{~mm})$ of rapid 

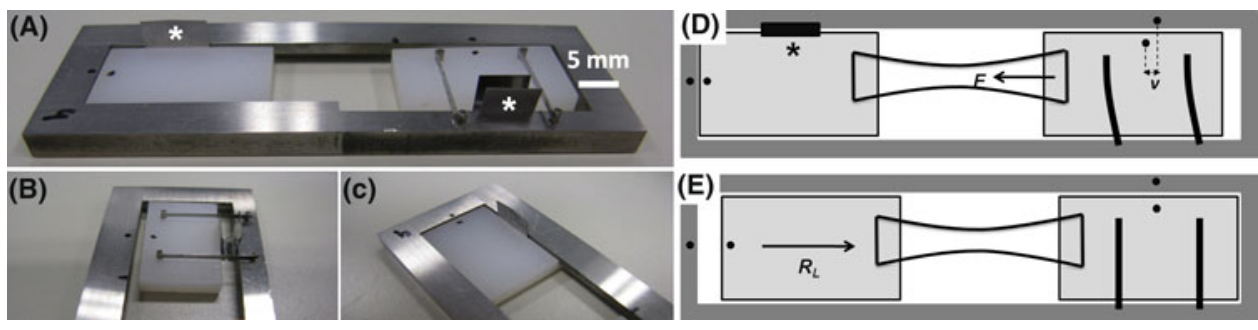

Fig. 1 Photographs $(\mathbf{a}, \mathbf{b}, \mathbf{c})$ and a schematic overview $(\mathbf{d}, \mathbf{e})$ of the model system in which generated force $(F, \mathbf{b}, \mathbf{d})$ and retraction $\left(R_{L}\right.$, c, e) can be measured through the displacement (v) of two sliding blocks positioned opposite from each other (With permission from

degrading nonwoven polyglycolic acid (PGA) (Concordia Manufacturing Inc., Coventry, RI, USA) coated with poly-4hydroxybutyrate $(\mathrm{P} 4 \mathrm{HB}$, received through collaboration with the University Hospital Zurich) as described previously (Mol et al. 2005). In summary, the scaffolds were attached to the two sliding blocks with polyurethane-tetrahydrofuran glue (15\% wt/vol). Sterilization was achieved by $70 \%$ ethanol incubation for $30 \mathrm{~min}$. Cells were seeded at passage 7 with a seeding density of 15 million cells per $\mathrm{cm}^{3}$ using fibrin as a cell carrier (Mol et al. 2004). The TE constructs were cultured for 4 weeks. During tissue culture, the medium was supplemented with L-ascorbic acid 2-phosphate $(0.25 \mathrm{mg} / \mathrm{ml}$; Sigma, St. Louis, MO, USA) and replaced twice a week.

\subsection{Force generation and retraction}

Both force generation and retraction were quantified in Matlab (The MathWorks, Eindhoven, The Netherlands) based on the displacement of the sliding blocks, using photographs made underneath a stereomicroscope (Zeiss Observer, Zeiss, Göttingen, Germany) (Van Vlimmeren et al. 2011). The leaf springs are an elastic joint, so plastic deformation does not occur. Every model system was calibrated with its own forcedisplacement curve by which force could be quantified with an error of $8.7 \%$. Retraction was defined as the percentage of shrinkage compared to the length of the TE construct at time of release of the constraints.

\subsection{Experimental design}

After 4 weeks of culture, the generated force was quantified based on the displacement of the leaf springs compared to day 0 . Changes in force and retraction were compared to control TE constructs that did not undergo any treatment.

In the first experiment, the active cellular contribution to the generated force and retraction was investigated $(n=4-8$ per group). The TE constructs were incubated $2 \mathrm{~h}$ with $50 \%$ FBS to maximize cellular activity, $10 \mu \mathrm{M}$ cytochalasin D (Sigma) to disrupt the actin network of the cells, and $10 \mu \mathrm{M}$
(Van Vlimmeren et al. 2011)). * indicates clamps that can be used to fix one or both of the sliding blocks. In this study, only the left sliding block was fixed during culture and the clamp was removed to measure retraction
Y-27632 (Sigma) to inhibit the ROCK pathway. After incubation with these biochemicals, the change in force was quantified. Next, constraints were released and tissue retraction was measured during $2 \mathrm{~h}$ with time intervals of $15 \mathrm{~min}$. Subsequently, the TE constructs were washed twice with PBS and received fresh tissue culture medium, except for the FBS samples which obtained fresh 50\% FBS medium. Then, further retraction was measured to examine the recovery from CytoD and the ROCK inhibitor, and maximum retraction in the FBS group. During the first $8 \mathrm{~h}$, retraction was measured every $30 \mathrm{~min}$, followed by measurements at 24 and $48 \mathrm{~h}$.

As retraction was still substantial in this first experiment, we performed a second experiment in which cellular contribution was completely eliminated by lysation of the cells and complete decellularization of the tissue ( $n=5$ per group). Force was again measured before and after treatment, followed by retraction measurements. Retraction was measured every $15 \mathrm{~min}$ during the first $2 \mathrm{~h}$, followed by every $30 \mathrm{~min}$ up to $10 \mathrm{~h}$ and one final measurement after $24 \mathrm{~h}$.

\subsection{Lysation and decellularization}

Lysation and decellularization of the TE constructs was performed after 4 weeks of tissue culture. The TE constructs were washed three times with PBS, after which the cells were lysated by incubation with a detergent solution $(0.25 \%$ triton-X 100 (Merck, Schiphol-rijk, The Netherlands) $+0.25 \%$ sodium-deoxycholate (Sigma) $+0.02 \%$ EDTA (Sigma)) over night at $37^{\circ} \mathrm{C}$. The lysated samples were then washed in PBS and placed in medium to measure force and retraction. The decellularized samples were incubated with the detergent solution as well, after which cellular removal was established by nuclease treatments with Benzonase ${ }^{\circledR}$ Nuclease (Novagen ${ }^{\circledR}$, EMD Chemicals Inc., San Diego, USA). The TE constructs were incubated with subsequently $100 \mathrm{U} / \mathrm{ml}(5-8 \mathrm{~h}), 80 \mathrm{U} / \mathrm{ml}$ (overnight), and $20 \mathrm{U} / \mathrm{ml}(5-8 \mathrm{~h}$ ) of Benzonase ${ }^{\circledR}$ in $50 \mathrm{mM}$ TRIS-HCL buffer (Sigma). Finally, they were washed with PBS and placed in medium to measure force and retraction. 


\subsection{Immunocytochemistry and immunohistochemistry}

The effect of $50 \%$ FBS, CytoD, and ROCK inhibitor on the actin network of the cells was evaluated by a whole-mount F-actin staining ( $n=2$ per group). In brief, after $2 \mathrm{~h}$ of incubation with the biochemicals, the TE constructs were washed three times with PBS for $5 \mathrm{~min}$, followed by fixation with $3.7 \%$ formaldehyde (Merck) for $40 \mathrm{~min}$. Next, samples were permeabilized with $0.5 \%$ Triton-X 100 (Merck) for $30 \mathrm{~min}$. Subsequently, the TE constructs were incubated with Phalloidin-TRITC (1:500, Sigma) for $60 \mathrm{~min}$, after which they were washed 3 times with PBS for $5 \mathrm{~min}$. Finally, the TE constructs were incubated with $4^{\prime}$,6-diamidino-2-phenylindole (DAPI) for $15 \mathrm{~min}$, washed three times with PBS for $5 \mathrm{~min}$, and evaluated using a multiphoton microscope (Zeiss LSM 510 META NLO, Darmstadt, Germany) in Two-Photon-LSM mode.

The efficacy of cellular lysation and tissue decellularization was evaluated qualitatively by histological and immunofluorescent stainings ( $n=1$ per group). The TE constructs were fixated with $3.7 \%$ formaldehyde (Merck), embedded in paraffin, and cut in tissue sections of $10 \mu \mathrm{m}$. Samples were studied by hematoxylin and eosin (HE) staining for general tissue morphology and cellular content. Further, a DAPI staining was performed to check the presence or absence of cell nuclei. The HE staining was visualized using light microscopy (Axio Observer, Zeiss, Göttingen, Germany) and the DAPI staining was evaluated using fluorescence microscopy (Axiovert 200M, Zeiss, Göttingen, Germany).

\subsection{Biochemical composition of tissues}

The amount of DNA was assessed from all samples $(n=56)$. In control, lysated, and decellularized samples, the amount of sulfated glycosaminoglycans (GAGs) and collagen was determined as well to investigate the effect of lysation and decellularization on the ECM composition ( $n=4$ per group). Lyophilized tissue samples were digested in papain solution (100 mM phosphate buffer, $5 \mathrm{mM}$ L-cysteine, $5 \mathrm{mM}$ ethylenediaminetetraacetic acid (EDTA), and $125-140 \mu \mathrm{g}$ papain per $\mathrm{ml}$ ) at $60^{\circ} \mathrm{C}$ for $16 \mathrm{~h}$. DNA content was determined with the Hoechst dye method (Cesarone et al. 1979) and a standard curve of calf thymus DNA (Sigma). GAG content was determined with a modification of the assay described by Farndale et al. (1986) and a standard curve from chondroitin sulfate from shark cartilage (Sigma). In short, $40 \mu$ l of diluted sample, without addition of chondroitin AC lyase, chondroitin ABC lyase, and keratanase, was pipetted into a 96-well plate in duplicate. Subsequently, $150 \mu 1$ dimethylmethylene blue was added and absorbance was measured at $540 \mathrm{~nm}$. The hydroxyproline content was determined with an assay according to Huszar et al. (1980) and a reference of trans-4hydroxyproline (Sigma). A 1-to-8.9 ratio of hydroxyproline to collagen was assumed.

\subsection{Statistical analyses}

All data are presented as mean and their standard error of mean. One-way ANOVA, followed by a Tukey's multiple comparison post hoc test, was carried out to evaluate statistical differences. Statistical analyses were done using GraphPad Prism software (GraphPad Software, Inc, USA) and considered significant for $P$ values $<0.05$.

\section{Results}

\subsection{The effect of 50\% FBS, Cytochalasin D, and ROCK} inhibitor on force and retraction

Figure 2 gives an overview of representative immunofluorescent stainings of the actin fibers within the cells at 14 and $28 \mu \mathrm{m}$ tissue depths. Both control and FBS samples contained aligned and organized actin fibers. Incubation with CytoD disrupted the actin network. In the superficial surface layer $(14 \mu \mathrm{m})$, cells became completely rounded, while stretched cells with a fragmented actin network were observed deeper in the tissue $(28 \mu \mathrm{m})$. Incubation with ROCK inhibitor was less destructive for the actin network than CytoD. The actin network became less organized, but individual fibers could still be observed.

Figure 3 and Table 1 provide an overview of the force measured before (pre) and after (post) incubation with the biochemicals, and the absolute and relative change. On average, generated force after 4 weeks of culture was $39.4 \pm 2.3 \mathrm{mN}$. Incubation with FBS for $2 \mathrm{~h}$ had no effect on the generated force within the TE constructs, while incubation with CytoD and ROCK inhibitor significantly decreased the generated force by $7.7 \pm 0.7$ and $6.8 \pm 0.5 \mathrm{mN}$, respectively. There was no difference in the effect of treatment between CytoD or ROCK inhibitor, both reduced force by approximately $20 \%$. DNA content was similar in all groups, so cell density could not have caused differences in the generated force or changes to it (data not shown).

Retraction after release of the constraints occurred rapidly during the first $30 \mathrm{~min}$, after which it slowly continued (Fig. 5a). After $2 \mathrm{~h}$, retraction was higher in the FBS group than in the control samples. Incubation with CytoD and ROCK inhibitor decreased the amount of retraction compared to control samples. There was no significant difference between incubation with ROCK inhibitor or CytoD (Fig. 4b). An overview of the absolute retraction values is given in Table 1.

Retraction of the FBS samples remained higher up to $10 \mathrm{~h}$, but after $24 \mathrm{~h}$, retraction in control samples reached a similar level (Fig. 5). Two hours after refreshment of the medium, the ROCK inhibitor and CytoD samples started to recover. Recovery seemed faster in the ROCK inhibitor samples than 

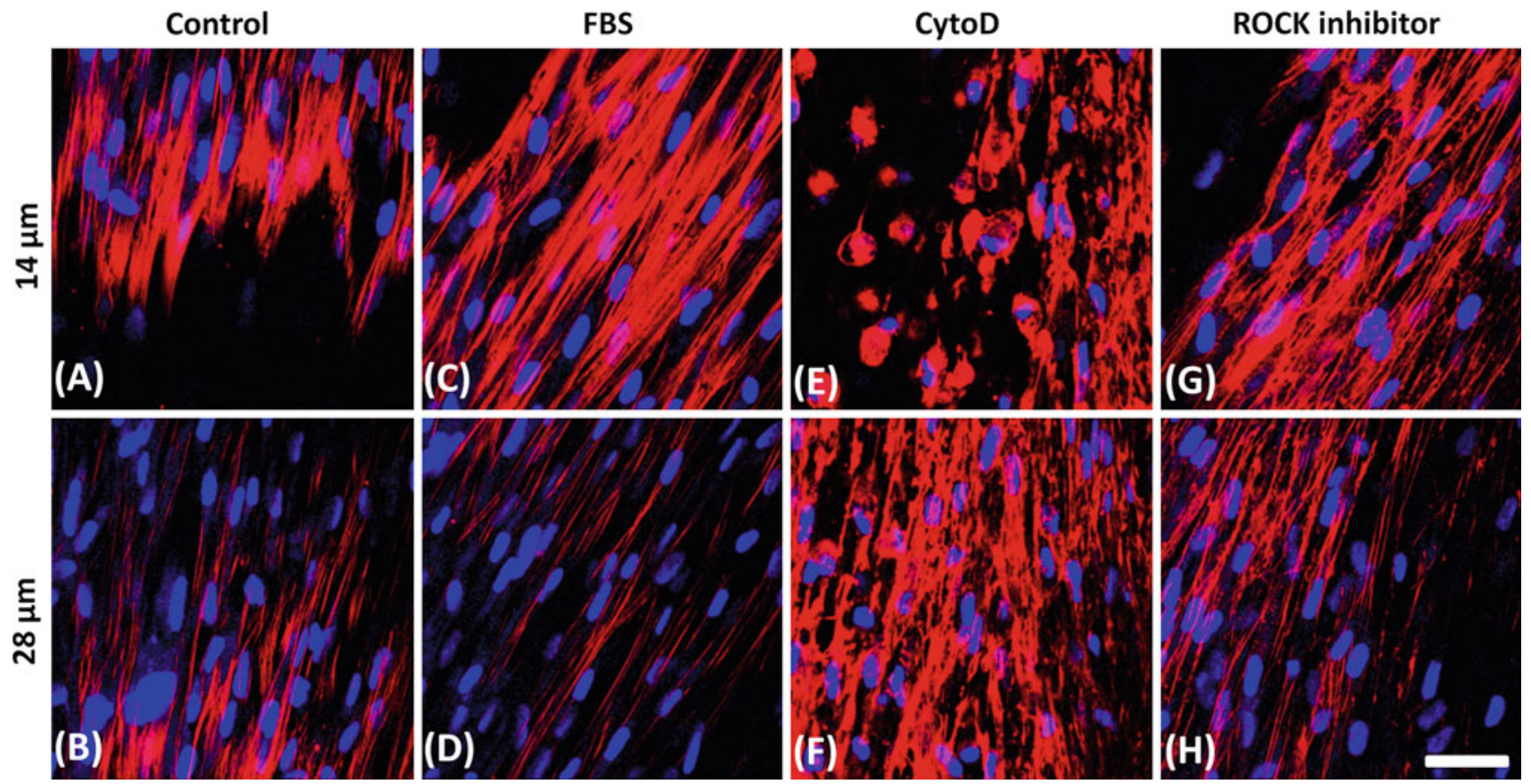

Fig. 2 Immunofluorescent stainings visualizing actin fibers (red) and cell nuclei (blue) in constrained control samples $(\mathbf{a}, \mathbf{b})$ and constrained samples treated with $50 \%$ FBS (c, d), CytoD (e,f) and ROCK inhibitor $(\mathbf{g}, \mathbf{h})$ for $2 \mathrm{~h}$. Control and FBS samples show aligned and organized fiber structures. Cells treated with CytoD become rounded at the surface layer and show a fragmented network at $28 \mu \mathrm{m}$. ROCK inhibitor causes a slight disruption of the actin fiber organization. The white bar represents $50 \mu \mathrm{m}$

Table 1 Absolute and relative force and retraction

\begin{tabular}{|c|c|c|c|c|c|c|c|}
\hline & \multicolumn{2}{|l|}{ Force change } & \multicolumn{5}{|c|}{ Retraction (\%) } \\
\hline & Absolute (mN) & Relative (\%) & $2 \mathrm{~h}$ & $\%$ Control $2 \mathrm{~h}$ & $10 \mathrm{~h}$ & $24 \mathrm{~h}$ & $48 \mathrm{~h}$ \\
\hline Control & $-1.1 \pm 0.3$ & $-2.8 \pm 0.6$ & $24.2 \pm 1.8$ & $100.0 \pm 7.7$ & $36.6 \pm 3.2$ & $42.4 \pm 5.7$ & $46.2 \pm 6.6$ \\
\hline FBS $2 \mathrm{~h}$ & $+0.7 \pm 0.8$ & $+1.1 \pm 2.4$ & $35.5 \pm 2.4^{*}$ & $146.6 \pm 10.0^{*}$ & $49.5 \pm 1.1^{*}$ & $51.7 \pm 1.8$ & $53.4 \pm 1.9$ \\
\hline CytoD 2h & $-7.7 \pm 0.7 * *$ & $-20.1 \pm 1.9 * *$ & $14.8 \pm 1.3 *$ & $61.0 \pm 5.4^{*}$ & $27.9 \pm 4.5$ & $34.4 \pm 5.9$ & $47.2 \pm 5.5$ \\
\hline ROCK $2 \mathrm{~h}$ & $-6.8 \pm 0.5^{* *}$ & $-21.0 \pm 3.2 * *$ & $14.7 \pm 1.0^{*}$ & $60.7 \pm 4.0 *$ & $31.7 \pm 1.5$ & $43.9 \pm 6.4$ & $61.4 \pm 4.9$ \\
\hline Control & $+0.1 \pm 0.6$ & $+0.2 \pm 1.6$ & $24.2 \pm 1.9$ & $100.0 \pm 7.7$ & $30.9 \pm 2.4$ & $34.0 \pm 2.7$ & \\
\hline Lysated & $-12.9 \pm 1.9 * *$ & $-27.3 \pm 3.4 * *$ & $4.2 \pm 0.7 * *$ & $17.5 \pm 2.7 * *$ & $4.3 \pm 0.8 * *$ & $5.1 \pm 0.9^{* *}$ & \\
\hline Decellularized & $-9.5 \pm 1.3^{*}$ & $-25.4 \pm 2.7^{*}$ & $3.7 \pm 0.3 * *$ & $15.2 \pm 1.3^{* *}$ & $5.9 \pm 0.6^{* *}$ & $5.9 \pm 0.5^{* *}$ & \\
\hline
\end{tabular}

*,** Significant difference of, respectively, $p<0.05$ and $p<0.001$ compared to control samples

in the CytoD samples. After $8 \mathrm{~h}$, retraction was no longer significantly lower than in the control samples.

\subsection{The effect of cell lysation and decellularization on force and retraction}

In the lysated constructs, the amount of DNA was similar to the control samples (Fig. 6a). The DAPI and HE stainings confirmed the presence of cells (Fig. 6e, h, k). Decellularized constructs contained hardly any detectable DNA (Fig. 6a), which was confirmed in the staining by the absence of cell nuclei in the DAPI staining and cells in the HE staining (Fig. 6f, i, 1). The amount of collagen remained unaffected by both lysation and decellularization (Fig. 6f, i, 1). There was a significant decrease in GAGs of both lysated and decellularized constructs compared to controls (Fig. 6c). This decrease was larger in the decellularized samples than in the lysated samples.

Lysation and decellularization decreased the generated force by $12.9 \pm 1.9$ and $9.8 \pm 1.2 \mathrm{mN}$, respectively (Fig. 7; Table 1). There was no difference between the effects of lysation and decellularization on the generated force. The relative decreases compared to the force before lysation and decellularization were, respectively, $27.3 \pm 3.4 \%$ and $25.4 \pm 2.7 \%$.

At release of constraints, retraction in the lysated and decellularized samples was substantially lower than in the 

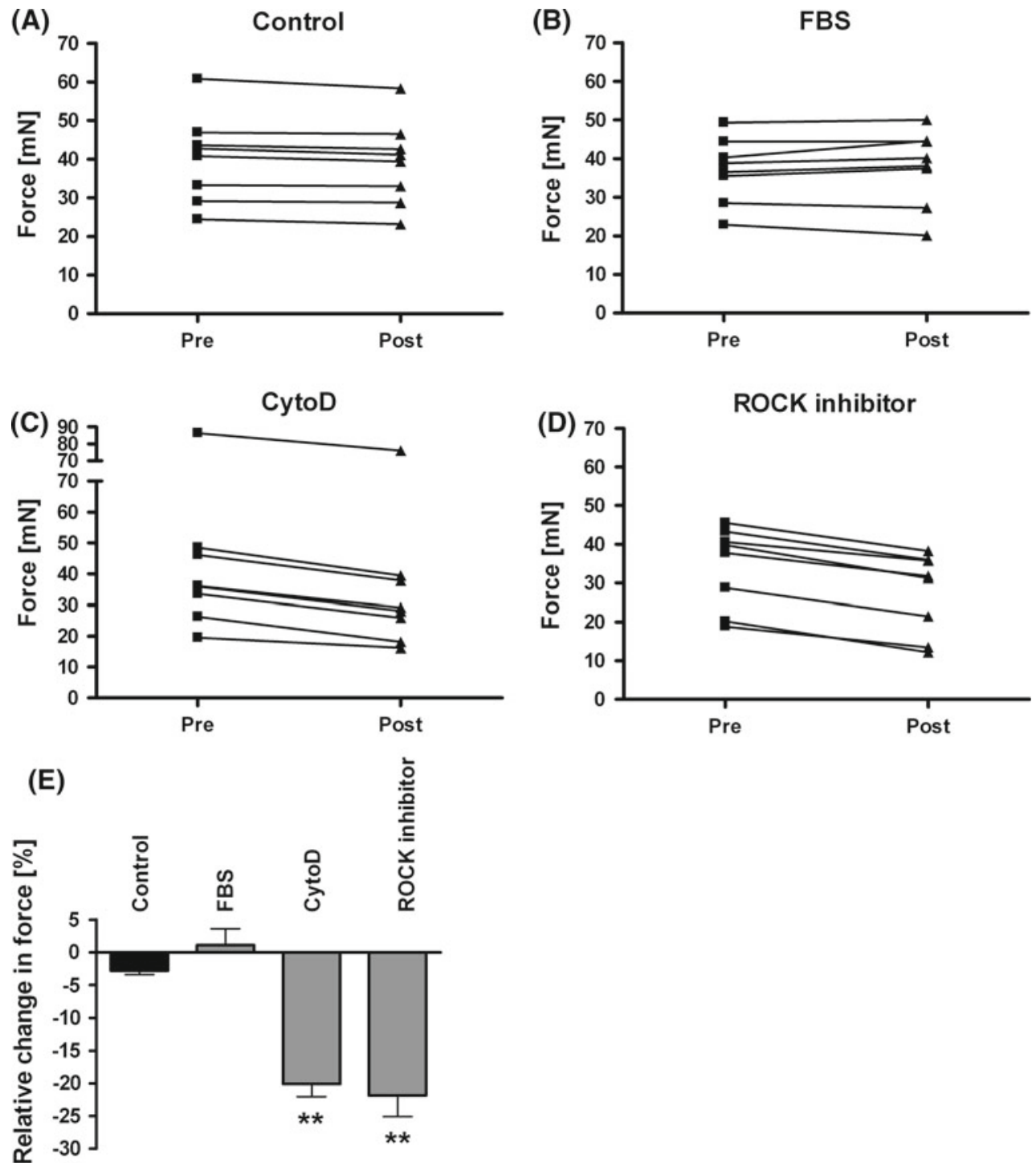

Fig. 3 Generated force in control samples (a) and before (pre) and after (post) incubation with 50\% FBS (b), CytoD (c), and ROCK inhibitor (d). e Change in force relative to the generated force before addition of

the biochemicals. Force remained constant in samples treated with $50 \%$ FBS and decreased in samples treated with CytoD and ROCK inhibitor. ** Significant difference of $p<0.001$ to control samples

control samples at 2, 10, and $24 \mathrm{~h}$ (Fig. 8). Retraction in the lysated and decellularized samples occurred in the first $30 \mathrm{~min}$, after which they remained stable, while control samples kept on retracting (Fig. 8). An overview of the absolute retraction values is given in Table 1.

\section{Discussion}

Cell-mediated compaction and retraction are general occurring phenomena in tissue engineering, mainly observed and investigated in fibrin and collagen gel systems. Within heart valve tissue engineering, cell traction forces lead to leaflet shrinkage, which, in vivo, results in regurgitation. The difference between an autologous tissue engineered heart valve

and the generally investigated gel systems is the presence of a biodegradable synthetic scaffold in the beginning of the culture period and a well-developed ECM that is synthesized by the cells after 4 weeks of tissue culture. As these two aspects complicate tissue retraction, thorough investigation of the problem is needed, before it can be solved. Previously, we have quantified the generation of force, stress, compaction, and retraction over time, and observed that the scaffold is able to resist the traction forces of the cells during the first 2 weeks. After 4 weeks of tissue culture, the scaffold is degraded and it was observed that a fully developed tissue compacts and retracts significantly, but less than the gel systems do (Van Vlimmeren et al. 2011). In this study, we aimed to quantify the contribution of the cells, as retraction is a 

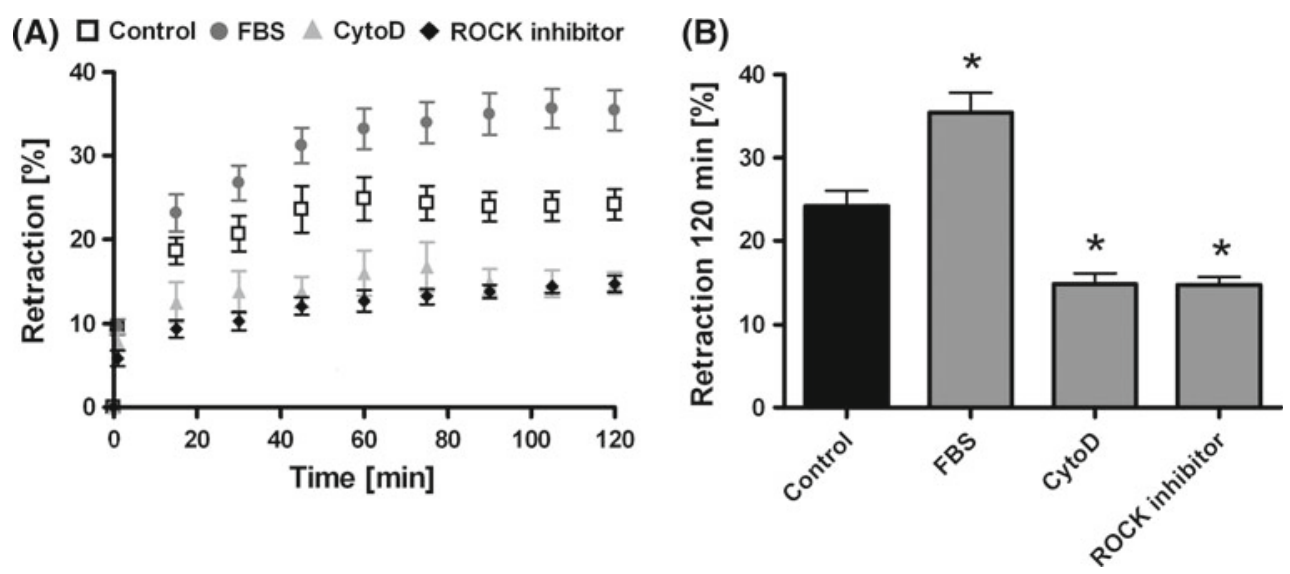

Fig. 4 a Tissue retraction during $2 \mathrm{~h}$ after release of constraints. b After $2 \mathrm{~h}$, retraction was higher in the FBS samples and lower in CytoD and ROCK inhibitor samples compared to the control samples. * Significant difference of $p<0.05$ to control samples
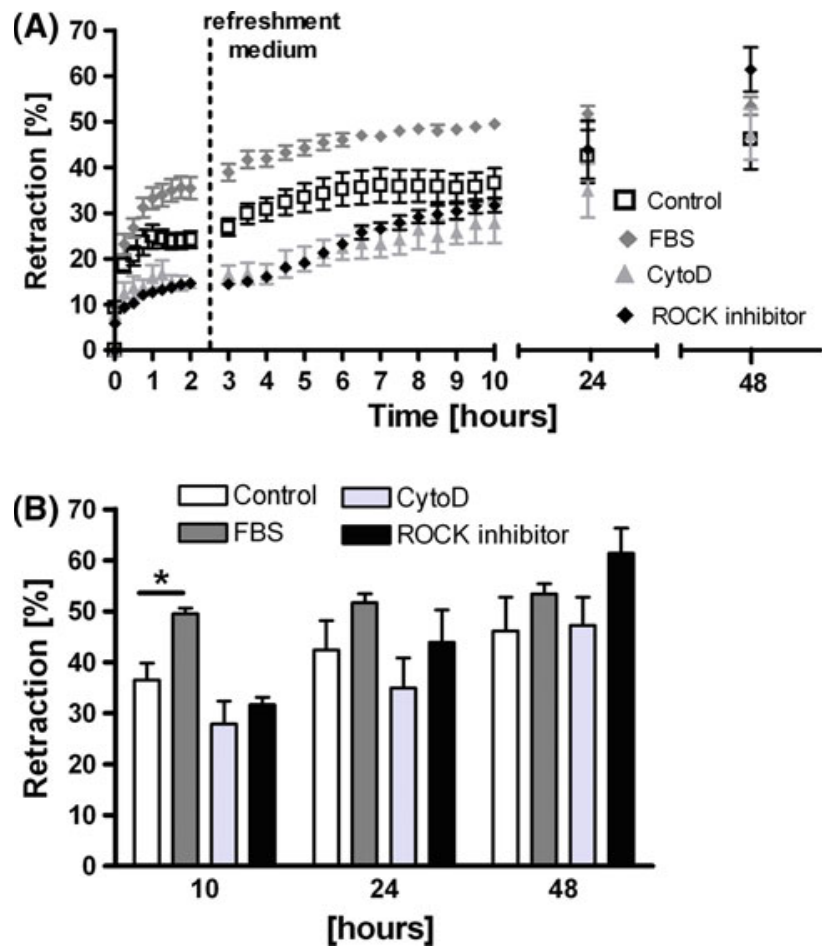

Fig. 5 a Tissue retraction and recovery from biochemicals over time. b After $8 \mathrm{~h}$ of recovery, retraction of CytoD and ROCK inhibitor samples was similar to control samples, while retraction of FBS samples was higher than control samples. At 24 and $48 \mathrm{~h}$, retraction was similar in all samples. * Significant difference of $p<0.05$ to control samples

cell-mediated problem. Therefore, we distinguished passive from active contributions to generated force and retraction, by changing traction forces.

\subsection{Passive and active components in force generation}

The generated forces measured within these experiments ranged from 20 to $60 \mathrm{mN}$. In previous experiments, this range of generated forces was also observed and we believe that it is caused by the natural biological variability of the TE constructs. As the net force is determined by both the mechanical integrity of the ECM and the force that the cells exert to it, it is not possible to ascribe this variability to one single tissue component. The ECM integrity is affected by the amount of collagen, collagen cross-links, and the organization of this fibrous network. Next to this, the number of cells that exert traction forces will affect the net force measured within the system.

Increasing the FBS concentration from 10 to $50 \%$ did not affect the generated force. It was predicted that increasing the FBS concentration would increase the generated force, as this was shown when increasing the FBS concentration from 0-10 to 20\% (Yee et al. 2001; Wakatsuki et al. 2000). FBS contains many growth factors, from which transforming growth factor- $\beta$ (TGF- $\beta$ ) is one that is known to induce cell traction forces (Wipff and Hinz 2009; Hinz 2006; Brown et al. 2002). Although TGF- $\beta$ probably is not the only growth factor in FBS that induces increased traction forces, for this particular growth factor it has been shown that there is an optimum working concentration between 7.5 and $15 \mathrm{ng} / \mathrm{ml}$. Concentrations above this optimum decreased the generated force (Brown et al. 2002). 50\% FBS could be above this optimum, but as it did increase tissue retraction, as discussed later, this is unlikely. More likely, at week 4 the ECM is strong enough to withstand the traction forces. In this case, a small increase in traction forces, due to increased FBS concentrations, will not affect the deformation much. However, when constraints are released, the organization of the ECM may be affected and it might loose its mechanical integrity. This would mean that the samples will be more prone to the increased traction forces and thus increased retraction might occur.

Incubation with CytoD or ROCK inhibitor decreased the generated force by $\sim 20 \%$ compared to control samples. 
(A)

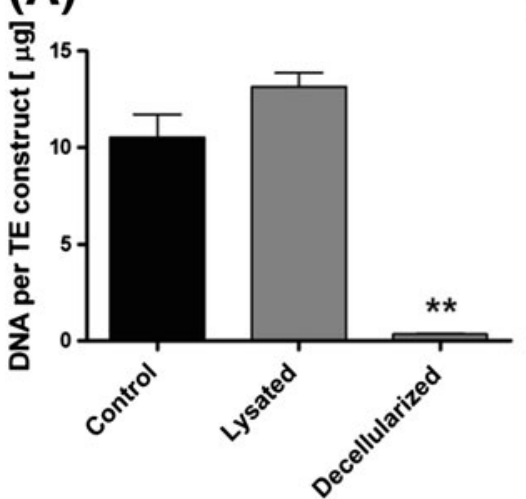

\section{Control}
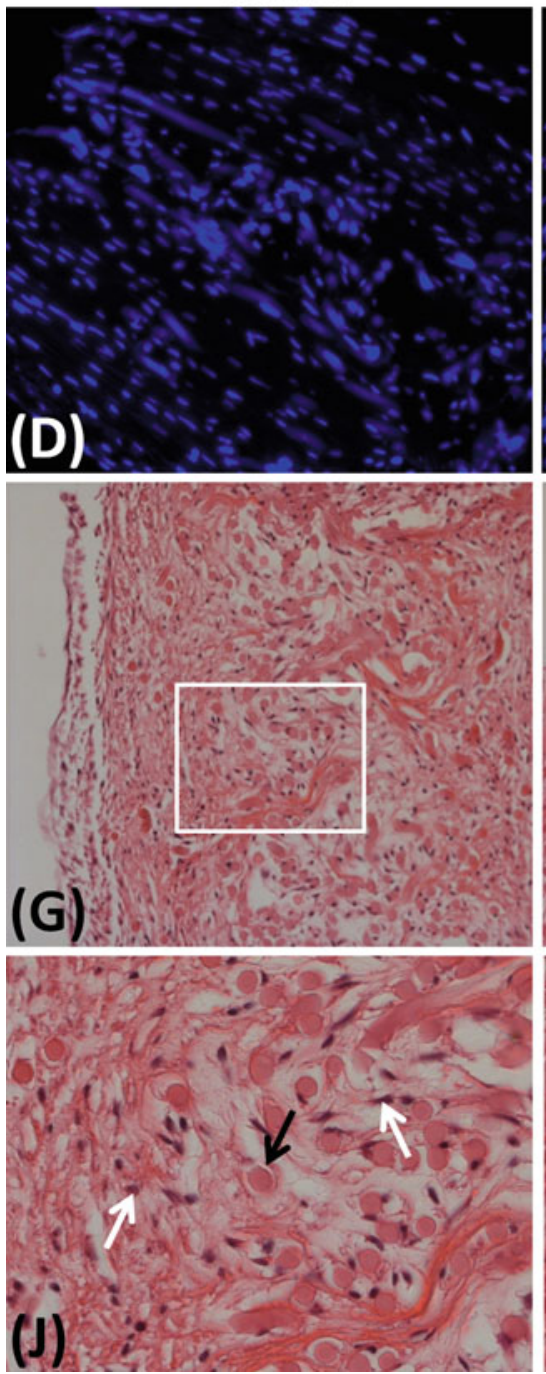

Fig. 6 DNA (a), collagen (b), and GAG (c) content, and DAPI (d-f) and HE (g-l) staining of control, lysated, and decellularized TE constructs. In the control and lysated samples, cells were present (small, dark dots indicated by the white arrows). In the decellularized
(C)

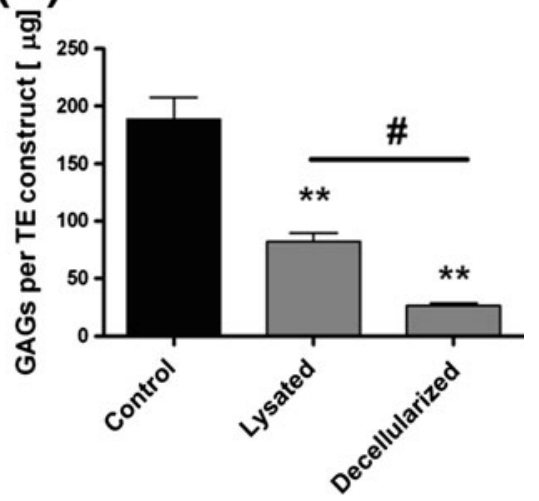

Decellularized
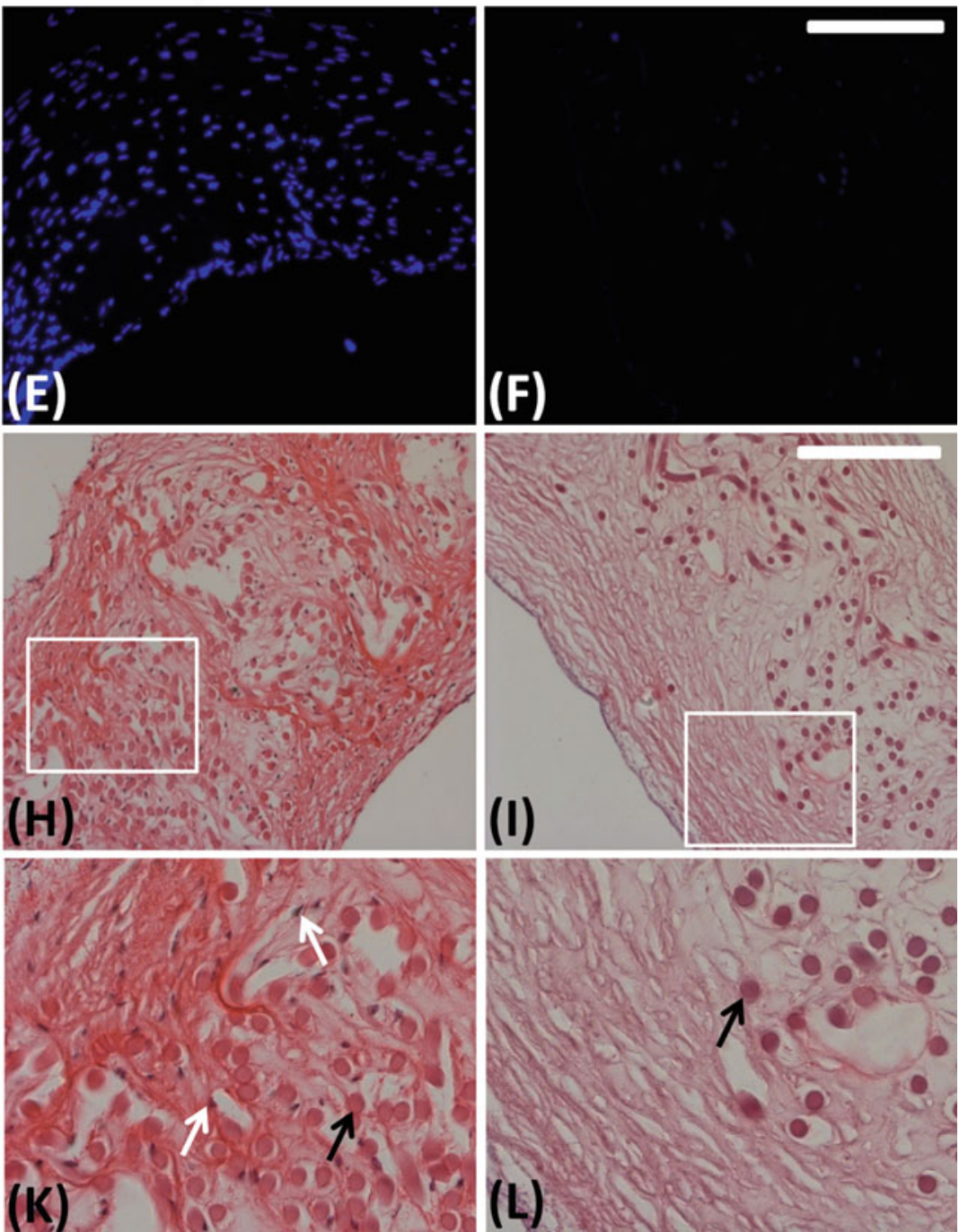

constructs, cells were absent. GAG content decreased in lysated and decellularized samples. The black arrows indicate scaffold remnants. ** Significant difference of $p<0.001$ to control samples. \# Significant difference of $p<0.05$. The white bars represent $200 \mu \mathrm{m}$ 

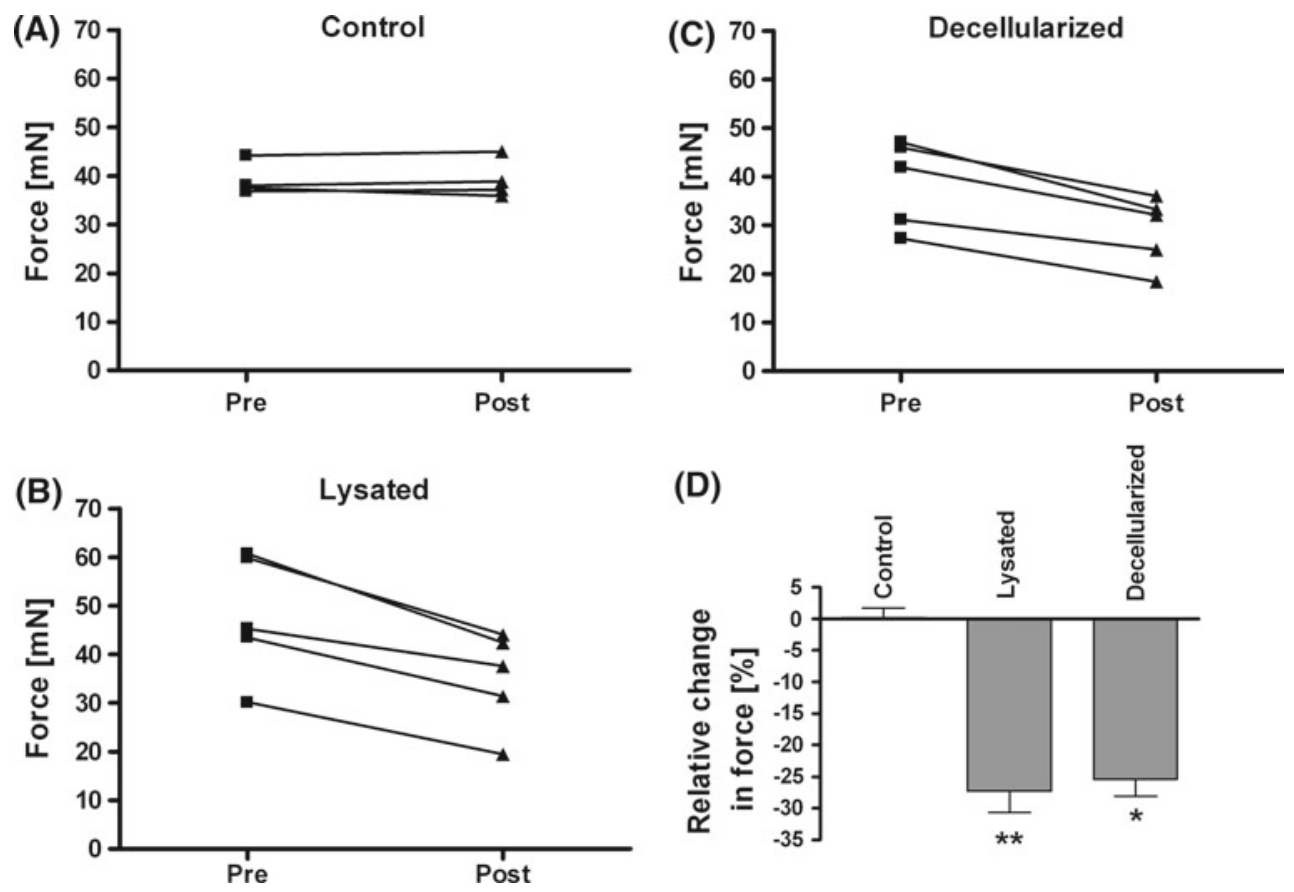

Fig. 7 Generated force in control samples (a) and before (pre) and after (post) lysation (b) and decellularization (c). $\mathbf{d}$ Change in force relative to the generated force before addition lysation and decellularization.

Although CytoD disrupts the complete actin network and ROCK inhibitor only inhibits myosin-actin contraction, there was no difference between the two treatments in generated force. The actin fiber network of the CytoD treated samples was fragmented compared to the ROCK inhibitor samples, where individual fibers were still present. To validate the elimination of cellular traction forces, we incubated TE constructs with CytoD for $16 \mathrm{~h}$, but this did not change the decrease in force (data not shown). These results suggest that how the cellular traction forces are eliminated is functionally indistinguishable. Next, we lysated and decellularized the TE constructs to eliminate potential remaining passive cell contributions. The resulting decrease in force was $\sim 26 \%$ and did not differ from the CytoD and ROCK inhibitor samples. In literature, the reported active and passive cellular contributions to generated force are much higher. The active cellular contribution to force of fibroblasts in collagen gels was 35-65\% (Marquez et al. 2009; Youssef et al. 2011; John et al. 2010; Legant et al. 2009) and lysation caused an additional $30 \%$ reduction of force below the level observed with CytoD treatment (Wakatsuki et al. 2000). To measure a decrease in force within our model system, bending of the leaf springs must become less and this requires elongation of the TE constructs. The $20-25 \%$ decrease in force that was measured required an elongation of $400-500 \mu \mathrm{m}$. As cells have remodeled the ECM to a certain length, the collagen fibers form an entangled network at that length and relaxation can only

Force decreased in the lysated and decellularized samples compared to the control samples. ** Significant difference of $p<0.001$ to control samples

occur up to a maximum. The $20-25 \%$ decrease in force that we obtained is closest to the observation of John et al., who observed a decrease of $\sim 35 \%$ after incubation with CytoD in a set-up that also used bending beams.

\subsection{Passive and active components in tissue retraction}

Two hours after release of constraints, retraction in the FBS samples was $\sim 45 \%$ higher than in the control samples. CytoD or ROCK inhibitor decreased retraction by $\sim 40 \%$ compared to control samples, and lysation and decellularization of the samples decreased retraction by $\sim 85 \%$. We have summarized these results in Fig. 9, illustrating activated retraction and a subdivision of normal retraction into active and passive components.

The decreases in retraction observed after treatment with CyotD and ROCK inhibitor or after lysation and decellularization are much greater than the decreases in the generated force. We believe that this is due to the relative weak leaf springs that were used in the model system. As mentioned in the previous section, a decrease in force requires an elongation of the tissue engineered construct, which is difficult as the ECM has been remodeled to a certain length. If the leaf springs would be stiffer, the required elongation would be minimal, which might result in a larger decrease of force after the treatment. 

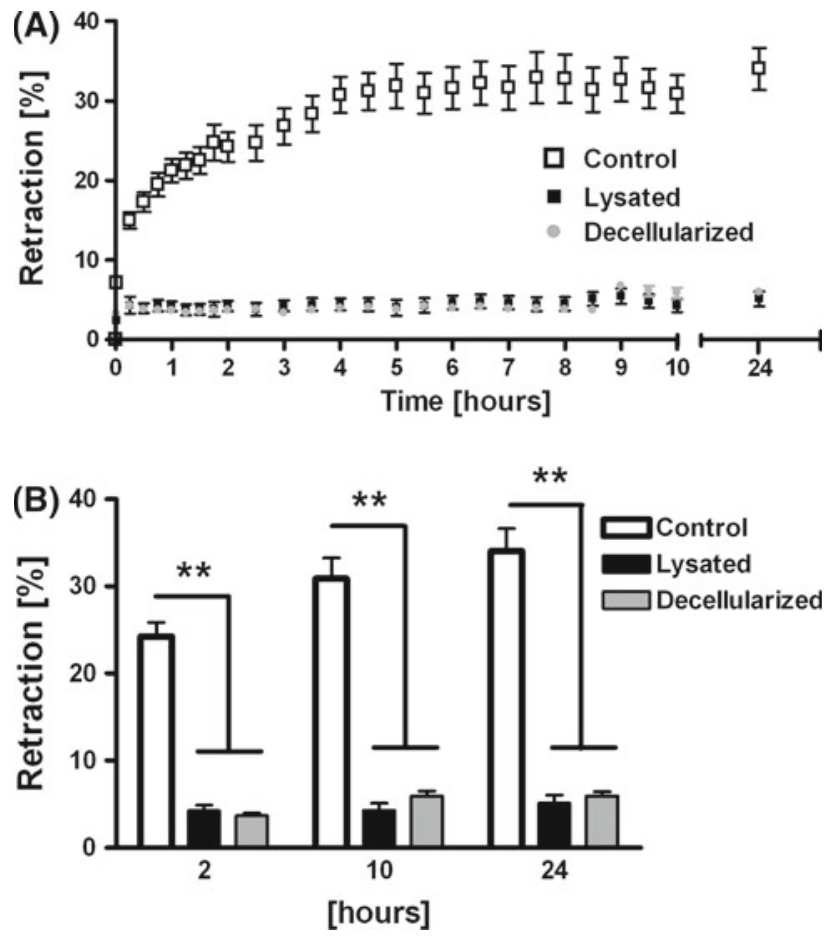

Fig. 8 a Tissue retraction during $24 \mathrm{~h}$ after release of constraints. b Retraction after 2, 10, and $24 \mathrm{~h}$ was less in the lysated and decellularized samples compared to control samples. ** Significant difference of $p<0.001$ to control samples

FBS increased tissue retraction by $45 \%$. The growth factor TGF- $\beta$, which we previously indicated to regulate traction forces of the cells, has also shown to increase retraction (Grouf et al. 2007). As in vivo plasma levels reach 55\% of serum, this increased retraction is important for the in vivo response of the cells after implantation. The high plasma level in vivo is likely to enhance cellular traction forces and retraction. However, in the end this will not result in more retraction in vivo as retraction of control samples reached similar levels as the FBS samples after $24 \mathrm{~h}$ in vitro, most likely caused by volume restrictions.

In fibroblast seeded fibrin gels, active retraction accounted for $\sim 75 \%$ of the total retraction (Grouf et al. 2007; Balestrini and Billiar 2009) and in collagen gels seeded with fibroblasts, this was $\sim 80 \%$ (Tomasek et al. 1992). Based on this literature, the active retraction in the TE constructs was less than expected. $16 \mathrm{~h}$ of incubation with CytoD, to check the elimination of traction forces, did not change retraction compared to $2 \mathrm{~h}$ of incubation (data not shown). Therefore, we eliminated passive cellular contributions as well by lysation and decellularization. Although passive cell behavior has been reported by others (Roy et al. 2009; Wakatsuki et al. 2000), it was not expected to contribute for $45 \%$ to retraction. In porcine arteries, elongation increased from 12 to $20 \%$ between CytoD treatment and decellularization (Roy et al. 2009). Passive contribution might arise from release of residual stress in the cells that form connections between fibers within the matrix or the space-occupying properties of the cells (Wakatsuki et al. 2000). However, both require that the cells remain elongated and connected to the ECM. For both ROCK inhibition and CytoD treatment, it was indeed shown that cells become irregular in shape, but retain their elongated cell configuration in this and other studies (Tomasek and Hay 1984; Tamariz and Grinnell 2002). The absence of differences between lysated and decellularized samples demonstrated that the presence of cellular material does not affect retraction once cells are lysated.

The residual stress within the ECM accounted for $15 \%$ of total retraction. This residual stress is likely developed during ECM remodeling of the cells, in which collagen fibers are re-organized and cross-links are formed. Cell lysation and decellularization decreased the amount of GAGs. As we have previously found that increased GAG content decreased the amount of retraction (unpublished data), the passive retraction of the ECM could have been overestimated in this study and partly be caused by the decrease in GAGs.
Fig. 9 Illustration of active and passive cell retraction, passive ECM retraction, and activated cell retraction in TE constructs. Active cell retraction accounts for $\sim 40 \%$ of total retraction, passive cell retraction accounts for $\sim 45 \%$ of total retraction, and passive residual stress in the ECM accounts for $\sim 15 \%$. Finally, activated cells increase retraction by $45 \%$

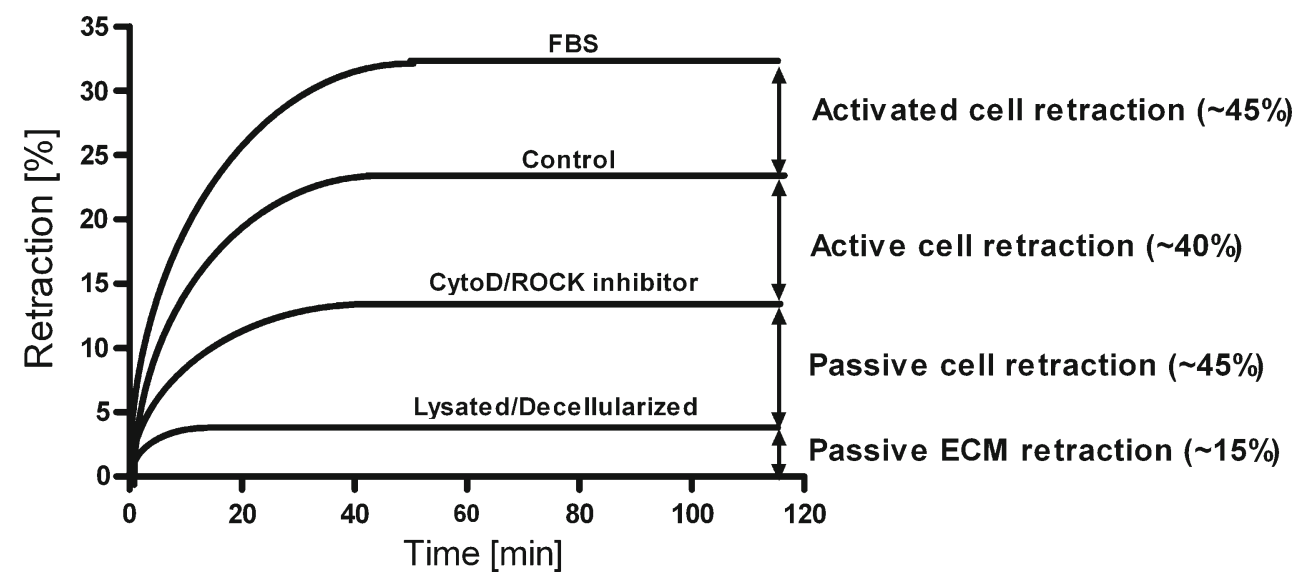




\subsection{Implications for heart valve tissue engineering}

We hypothesized that temporarily decreasing cellular traction forces at time of implantation might solve the problem of retraction. The results presented in this study demonstrate that this hypothesis does not hold. When eliminating the traction forces of the cells the TE constructs still retracted up to $15 \%$ within $2 \mathrm{~h}$. The hypothesis was based on the idea that loads applied during the cardiac cycle might be able to counterbalance the recovered traction forces once the valve is functioning in vivo. Maximum loading only occurs a very brief period every heart cycle, and further studies are needed to investigate whether this loading is enough to resist the continuous presence of the traction forces. As soon as the valve is implanted, cellular traction forces will recover. Recovery from CytoD and ROCK at 20\% FBS occurred within $8 \mathrm{~h}$ and in vivo this will likely be faster due to higher serum concentrations. A recent study of Seydain et al. confirms these expectations (Syedain et al. 2011). They treated fibrinbased tissue engineered heart valves with blebbistatin before implantation to decrease retraction. At implantation, these valves were functional, but after 4 weeks, regurgitation was moderate and at week 8 only one shortened leaflet was present. Minimizing cell vitality by treatment with sodium azide gave similar results, probably caused by proliferation of the remaining cells. These findings indicate that the cells become active again once they are implanted in vivo.

Decellularization or lysation reduced retraction to $\sim 4 \%$. Although this is still a lot, it is easier to correct for in the design of the heart valve as retraction occurs immediately upon release of constraints and remains stable after that. Implantation of a decellularized valve would represent a different approach, as it would require seeding of new non-contractile cells or the attraction of endogenous cells in vivo to ensure a viable implant. It is, however, a promising approach as decellularized valves have already shown functionality in vivo (Simon et al. 2003; Cebotari et al. 2006; Erdbrugger et al. 2006; Hopkins et al. 2009) and it is currently under investigation for tissue engineered constructs as well (Dahl et al. 2011).

\section{Conclusion}

The active cellular contribution to the generated force after 4 weeks is at least 20\%. Passive retraction accounted for $60 \%$ of total retraction, of which $15 \%$ was residual stress in the ECM and $45 \%$ was passive cell retraction. Cellular traction forces account for the remainder of the retraction (40\%). These results indicate that the passive cell contribution to retraction should not be underestimated. Interpretation of passive cell retraction is difficult, as the effect of the biochemicals on the interaction between the cell and the matrix is uncertain. Further studies should focus on unraveling the basis of the passive cell retraction for fundamental understanding of the mechanism behind this phenomenon. Ideally, one would like to bypass the passive cell contribution, without lysation of the cells to maintain a viable implant. The residual stress in the ECM is small and might be overcome by design changes to the tissue engineered heart valve geometry. These results provide valuable insights into the passive and active components of tissue retraction and are crucial for solving leaflet retraction in heart valve tissue engineering.

Acknowledgments The authors gratefully acknowledge the support of the Smart Mix Program of the Netherlands Ministry of Economic Affairs and the Netherlands Ministry of Education, Culture and Science. The authors would like to thank Nicky de Jonge for the visualization of the actin staining and Linda Kock for performing the biochemical assays.

Open Access This article is distributed under the terms of the Creative Commons Attribution Noncommercial License which permits any noncommercial use, distribution, and reproduction in any medium, provided the original author(s) and source are credited.

\section{References}

Balestrini JL, Billiar KL (2009) Magnitude and duration of stretch modulate fibroblast remodeling. J Biomech Eng 131(5):05100510510059

Brown RA, Prajapati R, McGrouther DA, Yannas IV, Eastwood M (1998) Tensional homeostasis in dermal fibroblasts: mechanical responses to mechanical loading in three-dimensional substrates. J Cell Physiol 175(3):323-332

Brown RA, Sethi KK, Gwanmesia I, Raemdonck D, Eastwood M, Mudera V (2002) Enhanced fibroblast contraction of 3D collagen lattices and integrin expression by TGF-beta1 and -beta3: mechanoregulatory growth factors?. Exp Cell Res 274(2):310-322

Cebotari S, Lichtenberg A, Tudorache I, Hilfiker A, Mertsching H, Leyh R, Breymann T, Kallenbach K, Maniuc L, Batrinac A, Repin O, Maliga O, Ciubotaru A, Haverich A (2006) Clinical application of tissue engineered human heart valves using autologous progenitor cells. Circulation 114(1):I-132-I-137

Cesarone CF, Bolognesi C, Santi L (1979) Improved microfluorometric DNA determination in biological material using 33258 Hoechst. Anal Biochem 100(1):188-197

Dahl SL, Kypson AP, Lawson JH, Blum JL, Strader JT, Li Y, Manson RJ, Tente WE, DiBernardo L, Hensley MT, Carter R, Williams TP, Prichard HL, Dey MS, Begelman KG, Niklason LE (2011) Readily available tissue-engineered vascular grafts. Sci Transl Med 3(68):68-69

Dallon JC, Ehrlich HP (2010) Differences in the mechanism of collagen lattice contraction by myofibroblasts and smooth muscle cells. J Cell Biochem 111(2):362-369

Dugina V, Fontao L, Chaponnier C, Vasiliev J, Gabbiani G (2001) Focal adhesion features during myofibroblastic differentiation are controlled by intracellular and extracellular factors. J Cell Sci 114(18):3285-3296

Erdbrugger W, Konertz W, Dohmen PM, Posner S, Ellerbrok H, Brodde OE, Robenek H, Modersohn D, Pruss A, Holinski S, Stein-Konertz M, Pauli G (2006) Decellularized xenogenic heart valves reveal remodeling and growth potential in vivo. Tissue Eng 12(8):20592068 
Farndale RW, Buttle DJ, Barrett AJ (1986) Improved quantitation and discrimination of sulphated glycosaminoglycans by use of dimethylmethylene blue. Biochim Biophys Acta 883(2):173-177

Flanagan TC, Cornelissen C, Koch S, Tschoeke B, Sachweh JS, Schmitz-Rode T, Jockenhoevel S (2007) The in vitro development of autologous fibrin-based tissue-engineered heart valves through optimised dynamic conditioning. Biomaterials 28(23):33883397

Flanagan TC, Sachweh J, Frese J, Schnoering H, Gronloh N, Koch S, Tolba R, Schmitz-Rode T, Jockenhoevel S (2009) In vivo remodelling and structural characterisation of fibrin-based tissue-engineered heart valves in the adult sheep model. Tissue Eng Part A 15(10):2965-2976

Follonier Castella L, Gabbiani G, McCulloch CA, Hinz B (2010) Regulation of myofibroblast activities: calcium pulls some strings behind the scene. Exp Cell Res 316(15):2390-2401

Gottlieb D, Kunal T, Emani S, Aikawa E, Brown DW, Powell AJ, Nedder A, Engelmayr GCJr, Melero-Martin JM, Sacks MS, Mayer JEJr (2010) In vivo monitoring of function of autologous engineered pulmonary valve. J Thorac Cardiovasc Surg 139(3): 723-731

Grouf JL, Throm AM, Balestrini JL, Bush KA, Billiar KL (2007) Differential effects of EGF and TGF-beta1 on fibroblast activity in fibrin-based tissue equivalents. Tissue Eng 13(4):799-807

Hinz B (2006) Masters and servants of the force: the role of matrix adhesions in myofibroblast force perception and transmission. Eur J Cell Biol 85(3-4):175-181

Hinz B, Gabbiani G (2003) Mechanisms of force generation and transmission by myofibroblasts. Curr Opin Biotech 14(5):538-546

Hoerstrup SP, Sodian R, Daebritz S, Wang J, Bacha EA, Martin DP, Moran AM, Guleserian KJ, Sperling JS, Kaushal S, Vacanti JP, Schoen FJ, Mayer JEJr (2000) Functional living trileaflet heart valves grown in vitro. Circulation 102(19 Suppl 3):III44-III49

Hopkins RA, Jones AL, Wolfinbarger L, Moore MA, Bert AA, Lofland GK (2009) Decellularization reduces calcification while improving both durability and 1-year functional results of pulmonary homograft valves in juvenile sheep. J Thorac Cardiovasc Surg 137(4):907-913

Huszar G, Maiocco J, Naftolin F (1980) Monitoring of collagen and collagen fragments in chromatography of protein mixtures. Anal Biochem 105(2):424-429

John J, Quinlan AT, Silvestri C, Billiar K (2010) Boundary stiffness regulates fibroblast behavior in collagen gels. Ann Biomed Eng 38(3):658-673

Kortsmit J, Rutten M, Wijlaars M, Baaijens F (2009) Deformation controlled load application in heart valve tissue-engineering. Tissue Eng Part C Methods 15(4):707-716

Legant WR, Pathak A, Yang MT, Deshpande VS, McMeeking RM, Chen CS (2009) Microfabricated tissue gauges to measure and manipulate forces from 3D microtissues. PNAS 106(25):1009710102

Marquez JP, Legant W, Lam V, Cayemberg A, Elson E, Wakatsuki $\mathrm{T}$ (2009) High-throughput measurements of hydrogel tissue construct mechanics. Tissue Eng Part C Methods 15(2):181-190

Mizutani T, Haga H, Kawabata K (2004) Cellular stiffness response to external deformation: tensional homeostasis in a single fibroblast. Cell Motil Cytoskelet 59(4):242-248

Mol A, Lieshout MI, Dam-de Veen CG, Neuenschwander S, Hoerstrup SP, Baaijens F, Bouten CV (2004) Fibrin as a cell carrier in cardiovascular tissue engineering applications. Biomaterials 26: 8

Mol A, Driessen NJ, Rutten MC, Hoerstrup SP, Bouten CV, Baaijens FP (2005) Tissue engineering of human heart valve leaflets: a novel bioreactor for a strain-based conditioning approach. Ann Biomed Eng 33(12):1778-1788
Mol A, Rutten MC, Driessen NJ, Bouten CV, Zund G, Baaijens FP, Hoerstrup SP (2006) Autologous human tissue-engineered heart valves: prospects for systemic application. Circulation 114(1 Suppl):I152-I158

Neidert MR, Tranquillo RT (2006) Tissue-engineered valves with commissural alignment. Tissue Eng 12(4):891-903

Nobe K, Nobe H, Yoshida H, Kolodney MS, Paul RJ, Honda K (2010) Rho A and the Rho kinase pathway regulate fibroblast contraction: enhanced contraction in constitutively active Rho A fibroblast cells. Biochem Biophys Res Commun 399(2):292-299

Robinson PS, Johnson SL, Evans MC, Barocas VH, Tranquillo RT (2008) Functional tissue-engineered valves from cell-remodeled fibrin with commissural alignment of cell-produced collagen. Tissue Eng Part A 14(1):83-95

Roy S, Thacher T, Silacci P, Stergiopulos N (2009) Arterial biomechanics after destruction of cytoskeleton by cytochalasin D. J Biomech 42(15):2562-2568

Ruel J, Lachance G (2009) A new bioreactor for the development of tissue-engineered heart valves. Ann Biomed Eng 37(4):674-681

Schmidt D, Dijkman PE, Driessen-Mol A, Stenger R, Mariani C, Puolakka A, Rissanen M, Deichmann T, Odermatt B, Weber B, Emmert MY, Zund G, Baaijens FP, Hoerstrup SP (2010) Minimallyinvasive implantation of living tissue engineered heart valves: a comprehensive approach from autologous vascular cells to stem cells. J Am Coll Cardiol 56(6):510-520

Simon P, Kasimir MT, Seebacher G, Weigel G, Ullrich R, Salzer-Nuhar U, Rieder E, Wolner E (2003) Early failure of the tissue engineered porcine heart valve SYNERGRAFT ${ }^{T M}$ in pediatric patients. Eur J Cardiothorac Surg 23:1002-1006

Sodian R, Hoerstrup SP, Sperling JS, Daebritz S, Martin DP, Moran AM, Kim BS, Schoen FJ, Vacanti JP, Mayer JEJr (2000) Early in vivo experience with tissue-engineered trileaflet heart valves. Circulation 102(90003):III-22-III-29

Stock UA, Nagashima M, Khalil PN, Nollert GD, Herden T, Sperling JS, Moran A, Lien J, Martin DP, Schoen FJ, Vacanti JP, Mayer JEJr (2000) Tissue-engineered valved conduits in the pulmonary circulation. J Thorac Cardiovasc Surg 119(4):732-740

Sutherland FW, Perry TE, Yu Y, Sherwood MC, Rabkin E, Masuda Y, Garcia GA, McLellan DL, Engelmayr GCJr, Sacks MS, Schoen FJ, Mayer JEJr (2005) From stem cells to viable autologous semilunar heart valve. Circulation 111(21):2783-2791

Syedain ZH, Tranquillo RT (2009) Controlled cyclic stretch bioreactor for tissue-engineered heart valves. Biomaterials 30(25):40784084

Syedain ZH, Lathi MT, Johnson SL, Robinson PS, Ruth GR, Bianco RW, Tranquillo RT (2011) Implantation of a tissue-engineered heart valve from human fibroblasts exhibiting short term function in the sheep pulmonary artery. Cardiovasc Eng Tech 2(2):11

Tamariz E, Grinnell F (2002) Modulation of fibroblast morphology and adhesion during collagen matrix remodeling. Mol Biol Cell 13(11):3915-3929

Tomasek JJ, Hay ED (1984) Analysis of the role of microfilaments and microtubules in acquisition of bipolarity and elongation of fibroblasts in hydrated collagen gels. J Cell Biol 99(2):536-549

Tomasek JJ, Haaksma CJ, Eddy RJ, Vaughan MB (1992) Fibroblast contraction occurs on release of tension in attached collagen lattices: dependency on an organized actin cytoskeleton and serum. Anat Rec 232(3):359-368

Van Vlimmeren MAA, Driessen-Mol A, Oomens CWJ, Baaijens FPT (2011) An in vitro model system to quantify stress generation, compaction and retraction in engineered heart valve tissue. Tissue Eng Part C Methods 17(10):8

Wakatsuki T, Kolodney MS, Zahalak GI, Elson EL (2000) Cell mechanics studied by a reconstituted model tissue. Biophys J 79(5):23532368 
Wipff P-J, Hinz B (2009) Myofibroblasts work best under stress. J Bodywork Mov Ther 13(2):121-127

Yee HFJr, Melton AC, Tran BN (2001) RhoA/rho-associated kinase mediates fibroblast contractile force generation. Biochem Biophys Res Commun 280(5):1340-1345
Youssef J, Nurse AK, Freund LB, Morgan JR (2011) Quantification of the forces driving self-assembly of three-dimensional microtissues. Proc Natl Acad Sci USA 108(17): 6993-6998. doi:10.1073/ pnas. 1102559108 